\title{
Estudo de associação entre antígenos leucocitários humanos e doença de Jorge Lobo
}

\author{
Study of the association between human leukocyte \\ antigens and Jorge Lobo's disease
}

\author{
Elaine Valim Camarinha Marcos ${ }^{1}$, Fabiana Covolo de Souza ${ }^{1}$, Elza Araújo Torres ${ }^{2}$, \\ José Roberto Pereira Lauris ${ }^{3}$ e Diltor Vladimir de Araújo Opromolla ${ }^{4}$
}

\begin{abstract}
RESUMO
A doença de Jorge Lobo é uma micose cutânea/subcutânea de evolução crônica, causada pelo fungo Lacazia loboi. Devido às características epidemiológicas e poucos estudos relacionados aos aspectos imunológicos dessa doença, o objetivo do trabalho foi investigar uma possível associação das especificidades HLA de classe II em 21 pacientes portadores da doença de Jorge Lobo, comparando com indivíduos sadios de mesma etnia. As tipificações HLA foram realizadas pelo método de PCR- SSP. O resultado não revelou qualquer tipo de associação entre os antígenos HLA e doença de Jorge Lobo. Embora sem significância estatística, foi observada a diminuição da freqüência do antígeno HLA-DR7 no grupo dos pacientes em relação aos controles ( $0 \%$ x 18\%), sugerindo uma associação negativa (protetora) entre HLA-DR7 e doença de Jorge Lobo. Contudo, estudos devem ser continuados, objetivando melhor entendimento nos mecanismos envolvidos na suscetibilidade e/ou proteção dessa doença.
\end{abstract}

Palavras-chaves: HLA. Doença de Jorge Lobo. Micose. Imunologia.

\begin{abstract}
Jorge Lobo's disease is a cutaneous/subcutaneous mycosis with a chronic course, caused by the fungus Lacazia loboi. Considering its epidemiology and the few studies on immunological aspects of this disease, the objective of the present study was to investigate a possible association between HIA class II specificities in 21 Jorge Lobo's disease patients, by comparing them with healthy individual of the same ethnic group. HLA typing was performed using PCR-SSP method. The result did not show any association between HLA antigens and Jorge Lobo's disease. Although not statistically significant, a decreased frequency of HLA-DR7 was observed in the patients compared to the controls ( $0 \%$ x 18\%). This suggests a negative association (protective) between HLA-DR7 and Jorge Lobo's disease. Further studies, however, are needed for a better understanding of the susceptibility and/or protection mechanisms involved.
\end{abstract}

Key-words: HLA. Jorge Lobo's disease. Mycosis. Immunology.

A doença de Jorge Lobo 5 é uma micose cutânea/subcutânea de evolução crônica, causada pelo Lacazia loboi ${ }^{14}$, 0 qual se assemelha filogenética e antigênicamente ao Paracoccidioides brasiliensis ${ }^{2}$. Há casos descritos em vários países da América Latina, mas ocorre predominantemente na região amazônica do Brasil, onde se encontram 295 dos 458 casos já relatados?.

A micose tem sido observada em brancos, negros e índios, e uma peculiaridade a ser ressaltada é que a doença de Jorge Lobo apresentava alta prevalência entre a população indígena da tribo Caiabi, quando eles habitavam o território situado entre os rios Arinos e Teles Pires, formadores do rio Tapajós no Estado do Mato Grosso. Ao serem transferidos para o Parque Nacional Indígena do Xingu não houve aparecimento de novos casos da doença entre os indivíduos da tribo. Esse dado sugere que outros fatores, como a prédisposição genética, estejam envolvidos no aparecimento da doença4.

Embora existam relatos de transmissão acidental e experimental da doença de Jorge Lobo na literatura, não existe comprovação de transmissão inter-humana da doença, principalmente

1. Equipe Técnica de Imunologia do Instituto Lauro de Souza Lima, Bauru, SP. 2. Hospital de Anomalias Crânio-Faciais da Universidade de São Paulo, Bauru, SP. 3. Faculdade de Odontologia da Universidade de São Paulo, Bauru, SP. 4. Divisão de Ensino e Pesquisa do Instituto Lauro de Souza Lima, Bauru, SP.

Endereço para correspondência: Dra. Elaine Valim Camarinha Marcos. Instituto Lauro de Souza Lima. Rod. Comandante João Ribeiro de Barros, km 225/26, Caixa Postal 3021, 17034-971 Bauru, SP.

Tel: 5514 3103-5871, Fax: 5514 3103-5914.

e-mail: imunologia@ilsl.br

Recebido para publicação em 4/6/2004

Aceito em 18/6/2005 
conjugal e familiar. Mesmo entre os índios Caiabi, não existem evidências de transmissão inter-humana, ao longo de 20 anos .

Lacaz cols ${ }^{4}$ chamaram a atenção para a variabilidade da resposta do hospedeiro à infecção causada pelo L loboi. Segundo os autores, alguns pacientes manifestam precocemente a forma disseminada da doença, enquanto outros apresentam lesão isolada ou localizada que assim permanece por longo tempo, ou indefinidamente. Entre essas duas situações haveria uma ampla variação no comportamento e na evolução da doença. Pouco se conhece sobre os aspectos imunológicos envolvidos nesta doença, possivelmente devido ao fato do agente etiológico não ser cultivável em meios artificiais até 0 momento ${ }^{14}$. Os mecanismos que favorecem a disseminação da micose e como ela ocorre não são conhecidos.

Os genes do complexo principal de histocompatibilidade (no homem, HLA), iniciam e controlam a resposta imune específica aos antígenos protéicos ${ }^{3}$ sendo que a maioria das doenças associadas ao HLAé resultado da interação entre fatores genéticos e 0 meio ambiente ${ }^{815}$. Assim, devido à alta prevalência da doença de Jorge Lobo na região amazônica brasileira, na sua alta incidência dentre os índios da tribo Caiabi e no fato de não haver transmissão inter-humana ${ }^{4}$, nós acreditamos que possa haver uma associação entre especificidades HLA e doença de Jorge Lobo.

Baseado nestas considerações e no pioneirismo deste tipo de investigação na doença de Jorge Lobo, nosso objetivo foi investigar a possível associação entre especificidades HLAe doença de Jorge Lobo, e comparar com indivíduos sadios de mesmo grupo étnico.

\section{MATERIAL E MÉTODOS}

Foram estudados 21 pacientes caucasóides brasileiros, portadores da doença de Jorge Lobo, oriundos do Estado do Acre, examinados pelo corpo clínico do Instituto Lauro de Souza Lima em Bauru, SP, com diagnóstico da micose confirmado pelo exame anatomopatológico.

0 grupo controle foi constituído por 50 indivíduos sadios, caucasóides da população do Estado do Acre, não aparentados, registrados como doadores de sangue do hemocentro de Rio Branc0, AC.

Extração DNA. Foi realizada a partir de células brancas do sangue venoso periférico pelo método de salting-out ${ }^{6}$.

Tipificação dos antígenos leucocitários humanos. HLA-DR (-DR1-16; 51,52,53) e -DQ (-DQ1-6) foram determinados pelo método de PCR-SSP, utilizando-se kits comercias de baixa e alta resolução (One-Lambda, USA) .

Análise estatística. As frequiências das especificidades $\mathrm{H} \mathrm{A}$ observadas em pacientes e controles foram comparadas por meio do teste exato de Fisher. Os valores corrigidos de $\mathrm{P}$ ( Pc) foram calculados multiplicando-se 0 valor de P pelo número de especificidades testadas ${ }^{13}$.

\section{RESULTAD0S}

Os fenótipos HLAdos 21 pacientes são apresentados na Tabela 1.

As freqüências antigênicas observadas nos 21 pacientes e nos controles, são apresentados na Tabela 2.

Aassociação significativa observada entre pacientes e controles, bem como o valor exato de P, são mostrados na Tabela 3. Adiferença foi com relação à freqüência diminuída do HLA-DR7, presente em $18 \%$ dos controles e ausente nos pacientes $(P=0,049)$. 0 valor de P relativo a essa comparação não permaneceu significativo após correção para o número de especificidades testadas $(\mathrm{Pc}=0,882)$.

Tabela 1 - Fenótipo HLAdos 21 pacientes com a doença de Jorge Lobo.

\begin{tabular}{lrrrrrrrr}
\hline Pac. & \multicolumn{2}{c}{ HLA- A } & \multicolumn{2}{c}{ HLA- B } & \multicolumn{2}{c}{ HLA- DR } & \multicolumn{2}{l}{ HLA- DQ } \\
\hline 1 & 69 & 31 & 57 & 61 & 4 & 8 & 3 & 4 \\
2 & 2 & - & 50 & 61 & 1 & 4 & 3 & 5 \\
3 & 2 & 30 & 51 & 57 & 3 & - & 2 & - \\
4 & 2 & 3 & 7 & 38 & 15 & 14 & 5 & 6 \\
5 & 3 & 29 & 7 & - & 15 & 9 & 2 & 6 \\
6 & 2 & 68 & 44 & 75 & 13 & 8 & 3 & 6 \\
7 & 25 & 32 & 44 & 35 & 1 & 4 & 3 & 5 \\
8 & 2 & - & 51 & 17 & 11 & - & 3 & 5 \\
9 & 24 & 31 & 62 & 35 & 1 & 11 & 5 & - \\
10 & 2 & 3 & 60 & - & 8 & 15 & 2 & 5 \\
11 & 68 & 11 & 7 & 14 & 1 & 15 & 5 & 6 \\
12 & 30 & 33 & 51 & 14 & 13 & 15 & 3 & 6 \\
13 & 2 & 69 & 27 & - & 3 & 13 & 3 & 6 \\
14 & 2 & 24 & 44 & 35 & 13 & 14 & 3 & 6 \\
15 & 2 & 24 & 35 & 60 & 4 & - & 3 & - \\
16 & 2 & 3 & 42 & 52 & 8 & 15 & 3 & 5 \\
17 & 1 & 3 & 18 & 57 & 1 & 4 & 3 & 5 \\
18 & 2 & 29 & 44 & 60 & 13 & 15 & 3 & 6 \\
19 & 29 & 31 & 35 & 62 & 4 & 16 & 3 & - \\
20 & 2 & 26 & 44 & 39 & 1 & 4 & 5 & - \\
21 & 2 & 30 & 7 & 39 & 9 & 16 & 2 & 5 \\
\hline & & & & & & & &
\end{tabular}

Tabela 2 - Freqüência fenotípica dos antígenos HIA-DR e DQ nos 21 pacientes e população controle do Estado do Acre.

\begin{tabular}{|c|c|c|}
\hline $\mathrm{HLA}$ & Doença de Jorge Lobo (\%) & Acre* (\%) \\
\hline DR1 & 28,6 & 20,0 \\
\hline DR3 & 9,5 & 16,0 \\
\hline DR4 & 33,4 & 34,0 \\
\hline DR7 & 0,0 & 18,0 \\
\hline DR8 & 19,0 & 16,0 \\
\hline DR9 & 9,5 & 4,0 \\
\hline DR10 & 0,0 & 4,0 \\
\hline $\mathrm{DR}_{5}$ & 9,5 & 14,0 \\
\hline $\mathrm{DR}_{12}$ & 0,0 & 0,0 \\
\hline $\mathrm{DR} 3_{6}$ & 23,8 & 20,0 \\
\hline $\mathrm{DR}_{6}$ & 9,5 & 6,0 \\
\hline $\mathrm{DR}_{2}$ & 33,4 & 18,0 \\
\hline $\mathrm{DR} 6_{2}$ & 9,5 & 18,0 \\
\hline DQ2 & 23,8 & 28,0 \\
\hline DQ3 & 57,1 & 74,0 \\
\hline DQ4 & 4,8 & 20,0 \\
\hline DQ5 & 47,7 & 32,0 \\
\hline $\mathrm{DQ6}_{1}$ & 38,0 & 30,0 \\
\hline
\end{tabular}

Tabela 3 - Diferenças estatísticas significantes observadas nas freqüências dos antígenos HLA entre pacientes (JL) e população controle do Estado do Acre (Ac).

\begin{tabular}{lcccc}
\hline HLA & $\begin{array}{c}\text { Freqüência doença } \\
\text { de Jorge Lobo (\%) }\end{array}$ & $\begin{array}{c}\text { Freqüência } \\
\text { Acre (\%) }\end{array}$ & P & Pc \\
\hline DR7 & 0,0 & 18,0 & 0,049 & $0 ., 882 \mathrm{~ns}$ \\
\hline
\end{tabular}

$\mathrm{P}=$ valor de $\mathrm{P}$, teste Exato de Fisher; $\mathrm{P} \leq 0,05$

$\mathrm{PC}=\mathrm{P}$ corrigido; $\mathrm{P} \leq 0,05$

ns $=$ não-significante 


\section{DISCUSSÃ0}

Neste trabalho, as frequiências dos antígenos HIA-DRe-DQ foram determinadas em 21 pacientes, com doença de Jorge Lobo. Dos pacientes estudados, 20 eram do sexo masculino com idade variando de 25 a 72 anos, e essa incidência pode ser explicada pelo fato de 0 homem dedicar-se mais às atividades rurais queas mulheres, ficando, assim, diretamente em contato com 0 agente etiológico.

A comparação das freqüências dos antígenos HLA observadas no grupo de pacientes com as determinadas nos controles, não revelou qualquer tipo de associação entre antígenos HLA e doença de Jorge Lobo. Embora a análise estatística não seja significativa ( $P_{c}>0,05$ ), é importante ressaltar a diminuição na frequiência do antígeno HLA-DR7 no grupo de pacientes com relação ao grupo controle ( $0 \%$ x 18\%), uma vez que, talvez, seja um indício de uma associação negativa (protetora) entre HLA-DR7 e doença de Jorge Lobo. Para confirmação deste dado, torna-se necessário uma amostra maior de pacientes e controles.

Ainda que para algumas doenças infecciosas um gene principal de suscetibilidade tenha sido proposto, a suscetibilidade para 0 agente infeccioso, bem como a patogênese da doença, são, geralmente, características multifatoriais. Em alguns casos, 0 componente genético não foi esclarecido, como na doença de Jorge Lobo, mas, para a maioria das doenças, os genes, seus produtos e 0 mecanismo de atuação estão sendo identificados. Dos genes que atuam na resposta imune, $0 \mathrm{HLA}$ parece estar mais relacionado à modulação da forma e manifestação clínica da doença do queà suscetibilidade para infecção propriamente dita? . Como exemplo, pode-se citar a paracoccidioidomicose ${ }^{10}$ e a hanseníase ${ }^{1112}$. A modulação da forma clínica da doença depende também, dos genes atuantes na imunidade inata, mas mecanismos protetores e de suscetibilidade dependem, provavelmente, de outros genes envolvidos e da natureza do patógen $0^{9}$.

\section{REFERÊNCIAS BIBLIOGRÁFICAS}

1. Fonseca OJM, Lacaz CS. Estudo de culturas isoladas de blastomicose queloidiforme (doença de Jorge Lôbo). Denominação ao seu agente etiológico. Revista do Instituto de Medicina Tropical de São Paulo 13:225-251, 1971.

2. Herr RA, Tarcha EJ, Taborda PRO, Taylor JW, Ajello L, Mendonza L. Phylogenetic analysis of Lacazia loboi places this previously uncharacterized pathogen within the dimorphic onygenales. Journal of Clinical Microbiology 39:309-314, 2001.

3. Klein J, Sato A. The HLA System. The New England Journal of Medicine 343:782-786, 2000.

4. Lacaz CS, Baruzzi RG, Rosa MCB. Doença de Jorge Lôbo. Universidade de São Paulo-IPSIS, São Paulo, 1986.

5. Lobo J0. Um caso de blastomicose produzido por uma espécie nova, encontrada em Recife. Revista Médica de Pernambuco 1:763-765, 1931.

6. Miller SA, Dykes DD, Polesky HF. A simple salting out procedure for extracting DNA from human nucleated cells. Nucleic Acids Research 16:1215-1218, 1988.

7. Opromolla DVA, Taborda PRO, Taborda VBA, Viana S, Furtado JE. Lobomicose: relato de 40 casos novos. Anais Brasileiros de Dermatologia 74:135-141, 1999.

8. Ottenhoff THM. Immunology of leprosy. Tropical and Geographical Medicine 46:72-80, 1994.

9. Petzel-Erler ML. Genetics of the immune responses and disease susceptibility. Ciência e Cultura ( São Paulo) 51: 199-211, 1999.

10. Restrepo FM, Restrepo MR, Restrepo AR. Blood groups and HLA antigens in paracoccidioidomycosis. Sabouraudia 21: 35-39, 1983.

11. Roy S, Frodsham A, Saha B, Hazra SK, Mascie-Taylor CG, Hill AV. Association of vitamin D receptor with leprosy type. Journal of Infectious Disease 179:187-191, 1999.

12. Schurr E, Morgan K, Gros P, Skamene E. Genetics of leprosy. The American Journal of Tropical Medicine and Hygiene 44:4-11, 1991.

13. Svejgaard A, Ryder LP. Association between HLA and disease. In: Dausset J, Svejgaard A (eds) HLAand disease, Copenhagen: Munksgaard, p.261-264, 1977.

14. Taborda PRO, Taborda VA, McGinnis MR. Lacazia loboi gen. nov., comb. nov., the etiologic agent of lobomycosis. Journal Clinical of Microbiology 37: 2031-2033, 1999.

15. Thorsby E, Ronninger KS. Particular HLA-DQ molecules play a dominant role in determining susceptibility of resistance to type I (insulin-dependent) diabetes mellitus. Diabetologia 36: 371-377 1993. 